\title{
Optimasi Produksi untuk Meminimasi Total Biaya pada Usaha Mikro Kecil Menengah
}

\author{
Adisti Rosmasari ${ }^{1}$, Wandhansari Sekar Jatiningrum ${ }^{2}$ \\ 1,2) Fakultas Teknologi Industri, Program Studi Teknik Industri, Universitas Ahmad Dahlan \\ Jl. Ringroad Selatan, Kragilan, Tamanan, Banguntapan, Bantul 55164 \\ Email: adistirosma79842@gmail.com, wandhansari.sekar@ie.uad.ac.id
}

\begin{abstract}
Micro, Small and Medium Enterprises (MSMEs) are the backbone of Indonesian economy. Therefore, it is considered important to notice the condition of MSMEs in Indonesia. The business process in MSMEs usually conducted traditionally, included in determining total amount of production. As a result, sometimes there is a buildup of inventory which causes an increase in the total production cost. On the other hand, lost sales can also occur due to the amount of production couldn't meet demand. This study aimed to solve production optimization problem with the objective function of minimizing total costs by considering inventory. It is expected that consumer demand can always be fulfilled and there is no overstock through optimization. A case study was conducted in Al-Barik MSME in Bantul Regency which produces various of snacks. Its strategic location makes Al-Barik MSME visited by tourists frequently to buy souvenirs, such as chips. This research was conducted using linear programming with LINGO. According to optimal solution, the minimum total cost spent on banana chips, bitter melon chips, and chili chips for a month was Rp. 98.227.900. Total inventory cost also decreased by an average $82.8 \%$ for each product during a month. The optimization made MSME's able to meet the demand for each product at each period. Therefore, the profit obtained from the three types of products increased by Rp. 3.061 .925 in a month.
\end{abstract}

Keywords: optimization, inventory, linear programming, total cost, MSME's

\begin{abstract}
Abstrak
Usaha Mikro Kecil Menengah (UMKM) merupakan tulang punggung dari perekonomian Indonesia. Untuk itu perhatian terhadap UMKM menjadi hal yang penting. Proses bisnis yang dilakukan UMKM biasanya bersifat tradisional. Salah satunya adalah dalam hal penentuan jumlah produksi. Akibatnya terkadang terjadi penumpukan inventori yang menyebabkan meningkatnya total biaya produksi. Di sisi lain, terkadang terjadi lost sales akibat jumlah produksi yang tidak mampu memenuhi permintaan. Penelitian ini bertujuan untuk menyelesaikan permasalahan optimasi produksi yaitu dengan tujuan meminimalkan total biaya. Selain itu inventori juga dipertimbangkan dalam penelitian ini agar tidak ada kekurangan produksi maupun kelebihan produksi. Studi kasus dilakukan pada UMKM Al-Barik di Kabupaten Bantul yang merupakan produsen makanan ringan. Lokasi yang strategis membuat UMKM Al-Barik sering dikunjungi oleh wisatawan untuk membeli oleh-oleh, seperti keripik. Penelitian dilakukan menggunakan linear programming dengan bantuan software LINGO. Berdasarkan hasil solusi optimal, didapatkan total biaya minimal yang dikeluarkan untuk keripik bonggol pisang, pare, dan peyek cabai selama sebulan yaitu sebesar Rp. 98.227.900. Total biaya simpan juga mengalami penurunan rata-rata sebesar $82,8 \%$ untuk setiap produk selama sebulan. Optimasi yang dilakukan membuat UMKM dapat memenuhi permintaan terhadap masing-masing produk pada tiap periode. Hal ini menyebabkan keuntungan yang diperoleh dari ketiga jenis produk meningkat sebesar Rp. 3.061.925.
\end{abstract}

Kata kunci: optimasi, inventori, linear programming, total biaya, UMKM 


\section{Pendahuluan}

UMKM (Usaha Mikro Kecil dan Menengah) merupakan salah satu usaha yang memiliki kemampuan untuk mengembangkan pergerakan ekonomi Indonesia. Selain itu, UMKM dalam pelaksanaannya menghasilkan omset besar atau bisa disebut "Tulang Punggung Perekonomian Indonesia" (Akhmad, et al., 2018). Menurut Mitchell \& Reid (2000), UMKM memiliki tingkat fleksibilitas yang baik sehingga mampu beradaptasi dan bertahan terhadap ketidakpastian bisnis. UMKM juga diyakini mampu mengurangi pengangguran dengan menyerap banyak tenaga kerja (Yanah et al,, 2018).

Hambatan terbesar dari bisnis UMKM adalah tingginya kompetisi yang terjadi dengan usaha skala besar maupun dengan sesama UMKM sendiri (Andriani et al., 2017). Agar dapat memiliki daya saing tinggi, UMKM perlu untuk selalu meningkatkan proses manajemen industrinya, seperti perencanaan, penggunaan sumber daya, pengendalian produksi, serta pengukuran dan evaluasi kinerja operasional (Moeuf et al., 2018).

Namun, proses manajemen industri yang dilakukan UMKM biasanya bersifat tradisional. Salah satunya adalah dalam hal penentuan jumlah produksi. Akibatnya terkadang terjadi penumpukan inventori yang menyebabkan meningkatnya total biaya produksi (Samudra et al., 2019). Di sisi lain, terkadang terjadi lost sales akibat jumlah produksi yang tidak mampu memenuhi permintaan. Untuk itu dibutuhkan analisis perhitungan yang tepat sehingga permintaan konsumen dapat terpenuhi, tanpa perlu adanya penumpukan inventori berlebih yang akan menimbulkan biaya tambahan.

Daerah Istimewa Yogyakarta yang terkenal sebagai tujuan wisata, memiliki banyak UMKM yang biasa dikunjungi oleh wisatawan (Wardiyanta et al., 2017). Salah satunya adalah UMKM Al-Barik yang merupakan produsen makanan ringan, seperti berbagai jenis keripik. Lokasi yang strategis membuat UMKM Al-Barik sering dikunjungi oleh wisatawan dengan tujuan untuk membeli oleh-oleh. Selama ini, pemilik UMKM hanya melakukan perkiraan saja untuk menentukan jumlah produksi setiap hari. Hal ini menyebabkan terkadang permintaan konsumen tidak dapat dipenuhi. Di sisi lain, terkadang terjadi penumpukan inventori di gudang. Apabila hal tersebut terjadi, maka akan timbul total biaya yang besar. Berdasarkan permasalahan tersebut, maka dibutuhkan penyelesaian permasalahan optimasi produksi.

Linear programming merupakan suatu metode penyelesaian satu fungsi tujuan dalam permasalahan optimasi. Linear programing mempertimbangkan kendala-kendala, pertidaksamaan dan banyaknya variabel dengan perhitungan berulang (iterasi) sampai mendapatkan solusi yang optimal (Haslan et al., 2018). Christian (2013) menggunakan Linear Programming untuk menentukan jumlah produksi pada tiga jenis produk sepatu untuk mendapatkan keuntungan optimal. Namun, dalam penelitian tersebut tidak dipertimbangkan inventori, dengan hasil yang didapatkan merupakan jumlah produksi dalam satu periode waktu. Hal serupa juga dilakukan pada penelitian Fathurohman (2019). Untuk itu penelitian ini bertujuan untuk menentukan jumlah produksi dan inventori optimal pada multi produk yang ada di UMKM sehingga dapat memenuhi permintaan konsumen dan meminimalkan total biaya.

\section{Metode Penelitian}

Studi kasus dilakukan di UMKM Al-Barik yang memproduksi berbagai jenis keripik. Pada penelitian ini, penentuan jumlah produksi dan inventori optimal dibatasi pada produk keripik bonggol pisang, pare, dan peyek cabai yang merupakan produk yang paling laku terjual. Penyelesaian Linear Programming dilakukan dengan bantuan software LINGO. Tahapan analisis perhitungan yang dilakukan adalah penentuan harga pokok produksi, pembuatan model matematis, dan analisis hasil

\section{Penentuan Harga Pokok Produksi}

Harga Pokok Produksi (HPP) merupakan biaya yang dikeluarkan perusahaan baik biaya secara langsung maupun tidak langsung, untuk menghasilkan nilai barang dalam kondisi tertentu sehingga barang dapat dijual. Penentuan HPP dilakukan sebelum perusahaan menetapkan harga jual. Harga ini nantinya digunakan untuk membandingkan pendapatan dalam laporan laba rugi (Maghfirah \& Syam, 2016). Penentuan HPP dilakukan berkaitan dengan perhitungan total biaya yang akan dilakukan. Dalam menentukan HPP terdapat 3 elemen biaya yang dipertimbangkan, 
diantaranya biaya bahan baku, biaya tenaga kerja langsung, dan biaya overhead.

\section{Penentuan Model Matematis}

Model matematis merupakan kumpulan keterkaitan variabel-variabel yang berbentuk formulasi atau fungsi persamaan dan atau pertidaksamaan yang mengekspresikan sifat pokok dari sistem dalam istilah matematika (Puspitasari et al., 2012). Pada penelitian ini model matematis yang digunakan yaitu menggunakan Linear programming metode simpleks. Metode simpleks dapat digunakan dalam pemecahan persoalan linear programming dengan banyak pertidaksamaan dan banyak variabel melalui perhitungan secara iterasi atau berulang-ulang (Rachman, 2017).

\section{Variabel Keputusan}

Variabel keputusan memiliki pengaruh yang besar terhadap nilai yang akan dicapai. Perlu adanya simbol matematika dalam penentuan variabel keputusan untuk menggambarkan tingkatan aktivitas penyelesaiannya. Variabel keputusan yang digunakan dalam penelitian ini adalah:

$X_{i t}=$ banyaknya produk $i$ yang diproduksi pada periode $t$ dalam satuan bungkus, dengan $\mathrm{i}=1$, 2, 3

$I_{i t}=$ banyaknya persediaan produk $\mathrm{i}$ yang diproduksi pada periode $t$ dalam satuan bungkus, dengan $i=1,2,3$

\section{Fungsi Kendala}

Fungsi kendala merupakan hubungan Linear dari variabel keputusan yang menunjukkan Batasan penyelesaian. Kendala dalam penelitian ini yaitu

\section{a. Kendala Permintaan}

Jumlah produk yang dihasilkan ditambahkan dengan persediaan produk sebelumnya dan persediaan produk saat ini harus sama dengan jumlah permintaan produk. Hal ini dilakukan agar permintaan untuk masingmasing produk pada tiap periode dapat terpenuhi. Persamaan 1 menunjukkan persamaan matematis untuk kendala permintaan.

$$
\sum_{i=1}^{j} \sum_{t=1}^{u} X_{i t}+I_{(i t-1)}-I_{i t}=Y_{i t} \quad \text { Pers. } 1
$$

Dengan, $\mathrm{i}=$ produk $1,2, \ldots, \mathrm{j} ; \mathrm{t}=$ periode 1 , $2, \ldots, \mathrm{u} ; X_{i t}=$ jumlah produk i pada periode $\mathrm{t}$; $I_{i t}=$ persediaan produk i pada periode $\mathrm{t} ; Y_{i t}=$ banyaknya permintaan produk i pada periode $\mathrm{t} ; I_{(i t-1)}=$ persediaan produk i ke $\mathrm{t}$ pada periode sebelumnya

\section{b. Kendala Bahan Baku}

Bahan baku yang tersedia setiap hari untuk menghasilkan produk memiliki keterbatasan. Persamaan 2 menunjukkan persamaan matematis kendala ketersediaan jumlah bahan baku

$$
\sum_{i=1}^{j} \sum_{t=1}^{u} \sum_{n=1}^{o} B B_{i n} X_{i t} \leq K B B_{t n}
$$

Pers. 2

Dengan, $\mathrm{n}=$ jenis bahan baku $1,2, \ldots, \mathrm{o}$; $B B_{i n}=$ jumlah bahan baku $\mathrm{n}$ yang dibutuhkan untuk tiap jenis produk i; $K B B_{t n}=$ kapasitas bahan baku $\mathrm{n}$ tiap jenis pada periode $t$

c. Kendala Waktu Tahapan Produksi

Tahapan produksi yang dilakukan untuk menghasilkan tiap jenis produk dibatasi oleh waktu. Persamaan 3 menunjukkan persamaan matematis untuk kendala ketersediaan waktu untuk tiap tahapan produksi.

$$
\sum_{i=1}^{j} \sum_{t=1}^{u} \sum_{m=1}^{n} T P_{i m} X_{i t} \leq K T P_{t m}
$$

Pers. 3

Dengan, $\mathrm{m}=$ tahapan produksi $1,2, \ldots, \mathrm{n}$; $T P_{i m}=$ waktu yang dibutuhkan jenis produk I pada tahapan produksi $\mathrm{m} ; K T P_{t m}=$ kapasitas waktu tersedia untuk tahapan produksi $\mathrm{m}$ pada periode $\mathrm{t}$

d. Kendala Kapasitas Produksi

Terdapat batasan maksimal produksi yang dapat dilakukan dalam sehari. Persamaan 4 menunjukkan kendala kapasitas produksi dalam sehari.

$$
X_{i t} \leq K P_{i t} \quad \text { Pers. } 4
$$

Dengan, $K P_{i t}=$ kapasitas produksi untuk produk i pada periode $\mathrm{t}$

\section{e. Kendala Kapasitas Inventori}

Tempat yang digunakan untuk menyimpan inventori memiliki keterbatasan. Persamaan 5 menunjukkan kendala kapasitas inventori. $I_{i t} \leq K I_{i t}$ Pers. 5 Dengan, $K I_{i t}=$ kapasitas inventory i pada periode $\mathrm{t}$

\section{f. Kendala Bilangan Integer}

Variabel keputusan harus berbentuk bilangan integer, yaitu bernilai bilangan bulat dan non negatif.

$$
X_{i t} \geq 0 \text {. }
$$




\section{Fungsi Tujuan}

Berdasarkan kendala-kendala yang telah diuraikan, maka fungsi tujuan Linear programming yang dibuat yaitu untuk meminimumkan biaya total, yaitu total biaya produksi dan biaya inventori. Hal ini dilakukan dengan menentukan nilai variabel keputusan berupa Keripik bonggol pisang $\left(\mathrm{X}_{1}\right)$, Keripik pare $\left(\mathrm{X}_{2}\right)$ dan peyek cabe $\left(\mathrm{X}_{3}\right)$, serta inventory keripik bonggol pisang $\left(I_{1}\right)$, inventory keripik pare $\left(I_{2}\right)$ dan inventory peyek cabai $\left(I_{3}\right)$ yang optimal. Nilai yang digunakan untuk hasil dari fungsi tujuan yaitu satuan nilai mata uang Rupiah (Rp).

$$
\min \mathrm{Z}=\sum_{i=1}^{j} \sum_{t=1}^{u} H_{i} X_{i t}+\sum_{i=1}^{j} \sum_{t=1}^{u} S_{i} I_{i t} \quad \text { Pers. } 6
$$

Dengan, $H_{i}=$ harga pokok produksi untuk tiap jenis produk i; $S_{i}=$ biaya simpan untuk tiap jenis produk i

\section{Asumsi dalam Linear Programming}

Dalam merumuskan model linear programming terdapat beberapa asumsi yang harus dipenuhi, yaitu:

a. Asumsi linieritas

Berdasarkan model linear programming yang dibuat, diketahui bahwa fungsi tujuan dan semua fungsi kendala yang digunakan merupakan bentuk fungsi linier

b. Asumsi additivitas

Pada fungsi tujuan yaitu minimasi total biaya, didapatkan melalui penjumlahan harga pokok produksi dan biaya simpan dari masing-masing produk. Hal ini menunjukkan model yang dibangun sudah memenuhi asumsi additivitas.

c. Asumsi kepastian

Semua parameter yang digunakan dalam model linear programming ini, seperti kebutuhan bahan baku, kapasitas bahan baku, kebutuhan waktu produksi, kapasitas waktu produksi, kapasitas jumlah produksi, kapasitas gudang, dan jumlah permintaan merupakan nilai yang bersifat deterministik.

d. Asumsi bilangan integer

Hasil variabel keputusan yang diperoleh dari model yang dibangun adalah berbentuk bilangan integer, yaitu bernilai nol atau positif.

\section{Verifikasi dan Validasi Data}

Tahapan verifikasi dilakukan untuk memeriksa apakah model formulasi yang dibuat sudah sesuai dan logis untuk digunakan. Hal ini dilakukan dengan cara memeriksa konsistensi dan kebenaran penggunaan notasi matematis. Setelah dilakukan tahapan verifikasi, tahapan validasi dilakukan untuk mengetahui apakah model formulasi yang dibuat sudah dapat merepresentasikan sistem nyata atau riil di lapangan. Pada penelitian ini, dilakukan pengujian terlebih dahulu terhadap permasalahan dengan data yang lebih sederhana untuk memastikan model formulasi yang dibangun sudah tepat.

\section{Analisis Hasil}

Analisis hasil output merupakan pembahasan hasil pengolahan data yang telah dilakukan dengan menggunakan metode simpleks berbantuan software Lingo 11. Pengolahan data dilakukan dengan menggunakan data histori permintaan, produksi, dan inventori yang dimiliki UMKM. Fungsi tujuan pada penelitian ini yaitu untuk meminimalkan total biaya melalui penentuan jumlah produksi dan ineventori yang optimal. Hasil optimasi dengan LINGO dibandingkan dengan kondisi riil di lapangan Pengolahan data juga dilakukan untuk menghitung besarnya keuntungan yang diperoleh UMKM ketika melakukan produksi secara riil dan secara optimasi.

\section{Hasil dan Diskusi}

Studi kasus dilakukan pada UMKM AI-Barik, Kabupaten Bantul yang memproduksi makanan ringan seperti keripik. Penelitian dilakukan untuk menentukan jumlah produksi dan inventori optimal pada 3 jenis produk, yaitu keripik bonggol pisang, pare, dan peyek cabai

Data yang dikumpulkan dalam penelitian ini, yaitu data permintaan histori, produksi, dan inventori selama sebulan, biaya bahan baku, biaya tenaga kerja, biaya overhead, jumlah kebutuhan bahan baku untuk produksi, kapasitas bahan baku tersedia, jumlah kebutuhan waktu tiap tahapan produksi, kapasitas waktu tersedia tiap tahapan produksi, kapasitas jumlah produksi, dan kapasitas gudang. 


\section{Pengumpulan Data}

\section{Data permintaan}

Tabel 1 menunjukkan data permintaan keripik bonggol, keripik pare, dan peyek cabai selama sebulan.

\section{Kebutuhan Bahan Baku}

Bahan baku yang digunakan dalam proses produksi di UMKM Al-Barik di antaranya, tepung terigu, tepung kanji, bonggol pisang, pare, cabai, garam, gula, kapur sirih, bawang putih dan minyak goreng. Rincian kebutuhan bahan baku untuk setiap produk dan kapasitas bahan baku yang tersedia setiap hari dapat dilihat pada Tabel 2.

Tabel 1. Data permintaan keripik bonggol, keripik pare dan peyek cabe selama sebulan (bungkus)

\begin{tabular}{|c|c|c|c|}
\hline $\mathbf{t}$ & $\begin{array}{c}\text { Keripik Bonggol } \\
\text { Pisang }\end{array}$ & $\begin{array}{c}\text { Keripik } \\
\text { Pare }\end{array}$ & $\begin{array}{c}\text { Peyek } \\
\text { Cabe }\end{array}$ \\
\hline 1 & 385 & 250 & 200 \\
\hline 2 & 400 & 295 & 220 \\
\hline 3 & 355 & 270 & 280 \\
\hline 4 & 335 & 340 & 220 \\
\hline 5 & 280 & 380 & 235 \\
\hline 6 & 360 & 300 & 220 \\
\hline 7 & 360 & 340 & 240 \\
\hline 8 & 460 & 310 & 200 \\
\hline 9 & 270 & 280 & 250 \\
\hline 10 & 280 & 260 & 240 \\
\hline 11 & 360 & 330 & 250 \\
\hline 12 & 380 & 340 & 220 \\
\hline 13 & 400 & 270 & 250 \\
\hline 14 & 310 & 270 & 190 \\
\hline 15 & 480 & 360 & 215 \\
\hline 16 & 370 & 330 & 250 \\
\hline 17 & 280 & 300 & 230 \\
\hline 18 & 310 & 300 & 260 \\
\hline 19 & 460 & 360 & 220 \\
\hline 20 & 330 & 340 & 235 \\
\hline 21 & 360 & 310 & 235 \\
\hline 22 & 380 & 320 & 270 \\
\hline 23 & 450 & 310 & 230 \\
\hline 24 & 420 & 330 & 250 \\
\hline 25 & 320 & 300 & 230 \\
\hline
\end{tabular}

Tabel 2. Kebutuhan bahan baku (gram)

\begin{tabular}{|l|c|c|c|c|}
\hline Bahan Baku & $\begin{array}{c}\text { Keripik } \\
\text { Bonggol } \\
\text { Pisang }\end{array}$ & $\begin{array}{c}\text { Keripik } \\
\text { Pare }\end{array}$ & $\begin{array}{c}\text { Peyek } \\
\text { Cabe }\end{array}$ & $\begin{array}{c}\text { Kap. } \\
\text { /Hari }\end{array}$ \\
\hline Tepung terigu & 4 & 4 & 7 & 5000 \\
\hline Tepung kanji & 2 & 2 & 4 & 3000 \\
\hline $\begin{array}{l}\text { Bonggol pisang } \\
\text { (buah) }\end{array}$ & 0.02 & - & - & 10 \\
\hline Kapur sirih & 8 & - & - & 4000 \\
\hline Cabe & - & - & 2 & 5000 \\
\hline Pare & - & 8 & - & 3000 \\
\hline $\begin{array}{l}\text { Minyak goreng } \\
\text { (liter) }\end{array}$ & 0.01 & 0.01 & 0.01 & 12 \\
\hline Bawang putih & 1 & 1 & 1 & 1000 \\
\hline Garam & 1 & 1 & 1 & 1000 \\
\hline Gula & 1 & 1 & 1 & 1000 \\
\hline
\end{tabular}

\section{Tahapan Produksi}

Proses produksi pada UMKM Al-Barik dilakukan secara berurutan. Kegiatan proses produksi dilakukan dengan tenaga manusia dan menggunakan peralatan sederhana. Masingmasing jenis produk memiliki proses produksi yang sama, tenaga kerja yang sama, namun untuk penggorengan dilakukan oleh pekerja yang berbeda dan alat yang berbeda. Tiap tahapan produksi membutuhkan waktu tertentu dan terdapat batasan waktu yang tersedia untuk produksi. Tabel 3 menunjukkan waktu yang dibutuhkan tiap tahapan produksi dan waktu tersedia.

Tabel 3. Tahapan tiap produksi (detik)

\begin{tabular}{|l|c|c|c|c|}
\hline \multicolumn{5}{|c|}{ Tahapan Proses Produksi (Detik) } \\
\hline & $\begin{array}{c}\text { Keripik } \\
\text { Bonggol }\end{array}$ & $\begin{array}{c}\text { Keripik } \\
\text { Pare }\end{array}$ & $\begin{array}{c}\text { Peyek } \\
\text { Cabe }\end{array}$ & Kap. \\
\hline $\begin{array}{l}\text { Penyiapan } \\
\text { Bahan Baku }\end{array}$ & 5 & 5 & 4 & 3600 \\
\hline $\begin{array}{l}\text { Pemotongan } \\
\text { bonggol }\end{array}$ & 60 & - & - & 30000 \\
\hline $\begin{array}{l}\text { Pemotongan } \\
\text { pare }\end{array}$ & - & 70 & - & 30000 \\
\hline $\begin{array}{l}\text { Pemotongan } \\
\text { Cabe }\end{array}$ & - & - & 30 & 30000 \\
\hline $\begin{array}{l}\text { Pencucian } \\
\text { Bahan Baku }\end{array}$ & 4 & 5 & 4 & 4500 \\
\hline $\begin{array}{l}\text { Pembuatan } \\
\text { Adonan }\end{array}$ & 3 & 3 & 3 & 1800 \\
\hline $\begin{array}{l}\text { Penggorengan } \\
\text { Keripik }\end{array}$ & 55 & - & - & 25000 \\
\hline $\begin{array}{l}\text { Penggorengan } \\
\text { Keripik Pare }\end{array}$ & - & 50 & - & 25000 \\
\hline $\begin{array}{l}\text { Penggorengan } \\
\text { Peyek Cabe }\end{array}$ & - & - & 85 & 25000 \\
\hline $\begin{array}{l}\text { Pemberian } \\
\text { Rasa }\end{array}$ & 2 & 2 & - & 1800 \\
\hline Pengemasan & 5 & 5 & 10 & 3600 \\
\hline
\end{tabular}

\section{Kapasitas Produksi}

Perhitungan kapasitas produksi per hari didapatkan dengan mempertimbangkan jumlah pekerja, total jam kerja dalam sehari, dan total waktu produksi. Kapasitas produksi untuk keripik bonggol yaitu 430 bungkus/hari, keripik pare yaitu 417 bungkus/hari, dan peyek cabe yaitu sebesar 430 bungkus/hari.

\section{Kapasitas Gudang}

Kapasitas gudang ditentukan untuk mengetahui maksimal jumlah produk yang dapat disimpan di gudang. Menurut pemilik UMKM, kapasitas gudang yang dimiliki yaitu untuk sejumlah 100 bungkus untuk masing-masing produk.

Berdasarkan data yang telah dikumpulkan pada dilakukan pengolahan data. Tahapan 
pengolahan dan analisis data yang dilakukan adalah sebagai berikut:

\section{Perhitungan Harga Pokok Produksi}

UMKM Al-Barik dalam penentuan HPP mempertimbangkan 3 elemen biaya diantaranya biaya bahan baku, biaya tenaga kerja langsung, dan biaya overhead.

\section{a. Biaya bahan baku}

Perhitungan biaya bahan baku didapatkan dengan mengalikan penggunaan bahan baku dengan biaya bahan baku (Rp), sehingga didapatkan biaya pada Tabel 4 .

Tabel 4. Biaya bahan baku (Rp)

\begin{tabular}{|l|c|c|c|}
\hline \multicolumn{4}{|c|}{ Biaya bahan baku/bungkus } \\
\hline Bahan baku & $\begin{array}{c}\text { Keripik } \\
\text { bonggol } \\
\text { pisang }\end{array}$ & $\begin{array}{c}\text { Keripik } \\
\text { pare }\end{array}$ & $\begin{array}{c}\text { Peyek } \\
\text { cabe }\end{array}$ \\
\hline Tepung terigu (gr) & 480 & 500 & 600 \\
\hline Tepung kanji (gr) & 198 & 198 & 232 \\
\hline $\begin{array}{l}\text { Bonggol pisang } \\
\text { (buah) }\end{array}$ & 200 & - & - \\
\hline Kapur sirih (gr) & 16 & - & - \\
\hline Cebe (gr) & - & - & 126 \\
\hline Pare (gr) & - & 192 & - \\
\hline $\begin{array}{l}\text { Minyak goreng } \\
\text { (liter) }\end{array}$ & 3150 & 3150 & 3150 \\
\hline Bawang putih (gr) & 38 & 38 & 38 \\
\hline Garam (gr) & 6 & 15 & 6 \\
\hline Gula (gr) & 15 & 15 & 15 \\
\hline Total & 4103 & 4108 & 4167 \\
\hline
\end{tabular}

\section{b. Biaya tenaga kerja langsung}

Biaya tenaga kerja tiap orangnya dalam satu bulan yaitu sebesar Rp. 600.000. Rata-rata produksi per hari pada bulan Desember 2019 dan Januari 2020 keripik bonggol pisang yaitu 329 bungkus, keripik pare 282 bungkus, dan peyek cabai 209 bungkus. Untuk itu perhitungan biaya tenaga kerja per bungkus untuk tiap produk adalah sebagai berikut.

Biaya tenaga kerja keripik bonggol

$$
=\frac{2 \text { orang } *\left(R p \cdot \frac{600.000}{25 \text { hari }}\right)}{329 \text { bungkus }}=\text { Rp. } 146 / \text { bungkus. }
$$

Biaya tenaga kerja keripik pare

$$
=\frac{2 \text { orang } *\left(R p \cdot \frac{600.000}{25 \text { hari }}\right)}{282 \text { bungkus }}=\text { Rp. } 170 / \text { bungkus. }
$$

Biaya tenaga kerja peyek cabe

$$
=\frac{2 \text { orang } *\left(R p \cdot \frac{600.000}{25 h a r i}\right)}{209 \text { bungkus }}=\text { Rp.229/ bungkus. }
$$

\section{c. Biaya overhead}

Total biaya overhead untuk setiap produk per bulan adalah Rp. 300.000. Untuk itu perhitungan biaya overhead per bungkus untuk setiap produk adalah sebagai berikut.
Biaya overhead untuk keripik bonggol pisang

$$
=\frac{\left(R p \cdot \frac{3000.000}{25} \text { hari }\right)}{329 \text { bungkus }}=\text { Rp. 36/bungkus. }
$$

Biaya overhead untuk keripik pare

$$
=\frac{\left(R p \cdot \frac{300.000}{25 \text { hari }}\right)}{282 \text { bungkus }}=\text { Rp. 43/bungkus. }
$$

Biaya overhead untuk peyek cabe

$$
=\frac{\left(\frac{\text { Rp. } 300.000}{25 \text { hari }}\right)}{209 \text { bungkus }}=\text { Rp. } 57 / \text { bungkus }
$$

Berdasarkan perhitungan biaya bahan baku, biaya tenaga kerja langsung, dan biaya overhead untuk masing-masing produk, maka didapatkan harga pokok produksi untuk keripik bonggol sebesar Rp. 4.285/bungkus, keripik pare sebesar Rp. 4.321/bungkus, dan peyek cabai sebesar Rp. 4.453/bungkus.

\section{Biaya Simpan}

Menurut Mahardika, Ardiansyah, dan Yunus (2017), komponen biaya yang termasuk dalam biaya simpan di antaranya adalah biaya yang berhubungan dengan tempat penyimpanan seperti listrik dan pendingin udara, biaya kerusakan persediaan, biaya asuransi persediaan, biaya kehilangan, biaya pajak, biaya perhitungan fisik, dan biaya modal. Berdasarkan perhitungan yang dilakukan, didapatkan biaya simpan untuk keripik bonggol pisang, keripik pare, dan peyek cabai secara berturut-turut adalah Rp. 214, Rp. 216, dan Rp. 223 per bungkus/hari.

\section{Analisis dengan Linear Programming}

Pengolahan data dengan linear programming dilakukan untuk mengetahui jumlah produksi dan inventori optimal untuk setiap jenis produk pada tiap periode. Komponen-komponen yang digunakan dalam membangun model dengan linear programing adalah sebagai berikut.

\section{a. Variabel Keputusan}

$\mathrm{X}_{1 \mathrm{t}}=$ jumlah produksi keripik bonggol pisang pada periode $t$

$\mathrm{X}_{2 \mathrm{t}}=$ jumlah produksi keripik pare pisang pada periode $t$

$\mathrm{X}_{3 \mathrm{t}}=$ jumlah produksi peyek cabe pisang pada periode $\mathrm{t}$

$\mathrm{l}_{1 \mathrm{t}}=$ jumlah inventori keripik bonggol pisang pada periode $t$

$\mathrm{I}_{2 \mathrm{t}}=$ jumlah inventori keripik pare pisang pada periode $t$ 
$I_{3 t}=$ jumlah inventori peyek cabe pisang pada periode $t$

\section{b. Fungsi Tujuan}

Fungsi tujuan pada penelitian ini adalah minimasi total biaya yaitu jumlah total harga pokok produksi dan total biaya simpan dari ketiga jenis produk. Fungsi tujuan dibuat berdasarkan persamaan 6 untuk ketiga jenis produk.

$$
\begin{gathered}
\text { Min } Z=\left(\sum_{t=1}^{25} 4285 X_{1 t}+\sum_{t=1}^{25} 4321 X_{2 t}\right. \\
\left.+\sum_{t=1}^{25} 4453 X_{3 t}\right) \\
+\left(\sum_{t=1}^{25} 214 I_{1 t}+\sum_{t=1}^{25} 216 I_{2 t}+\sum_{t=1}^{25} 223 I_{3 t}\right)
\end{gathered}
$$

\section{c. Fungsi Kendala}

Fungsi kendala pada penelitian ini terdiri dari kendala permintaan tiap jenis produk, tahapan produksi, bahan baku, kapasitas produksi, dan kapasitas gudang.

1) Kendala permintaan

Kendala permintaan dibuat berdasarkan persamaan 1 untuk setiap jenis produk.

Keripik bonggol pisang:

$X_{1 t}+I_{10}-I_{i t}=Y_{1 t}$

$X_{1 t}+I_{(i t-1)}-I_{i t}=Y_{1 t}$

Keripik pare:

$X_{2 t}+I_{20}-I_{i t}=Y_{1 t}$

$X_{2 t}+I_{(i t-1)}-I_{i t}=Y_{2 t}$

Peyek cabe:

$X_{1 t}+I_{30}-I_{i t}=Y_{1 t}$

$X_{3 t}+I_{(i t-1)}-I_{i t}=Y_{3 t}$

$Y_{1 \mathrm{t}}, Y_{2 \mathrm{t}}$, dan $\mathrm{Y}_{3 \mathrm{t}}$, menunjukkan permintaan produk 1, 2, dan 3, yaitu produk keripik bonggol pisang, keripik pare, dan peyek cabe pada setiap periode t. Data permintaan masing-masing produk untuk tiap periode dapat dilihat pada Tabel 1 .

2) Kendala tahapan produksi

Kendala tahapan produksi dibuat berdasarkan persamaan 2 untuk setiap tahapan produksi yang dilakukan.

Tahapan penyiapan:

$5 X_{1 t}+3 X_{2 t}+2 X_{3 t} \leq 3600$

Tahapan pemotongan bonggol:

$60 X_{1 t} \leq 30000$

Tahapan pemotongan pare:

$70 X_{2 t} \leq 30000$

Tahapan pemotongan cabe:
$30 X_{3 t} \leq 30000$

Tahapan pencucian:

$4 X_{1 t}+5 X_{2 t}+4 X_{3 t} \leq 4500$

Tahapan pembuatan adonan:

$3 X_{1 t}+3 X_{2 t}+3 X_{3 t} \leq 3600$

Tahapan penggorengan bonggol:

$30 X_{1 t} \leq 25000$

Tahapan penggorengan pare:

$30 X_{2 t} \leq 25000$

Tahapan penggorengan peyek cabe:

$80 X_{3 t} \leq 25000$

Tahapan pemberian rasa:

$2 X_{1 t}+2 X_{2 t} \leq 1800$

Tahapan pengemasan:

$3 X_{1 t}+3 X_{2 t}+3 X_{3 t} \leq 3600$

3) Kendala bahan baku

Kendala bahan baku dibuat berdasarkan persamaan 3 untuk setiap jenis bahan baku yang digunakan untuk ketiga jenis produk.

Tepung terigu:

$4 X_{1 t}+4 X_{2 t}+7 X_{3 t} \leq 5000$

Tepung kanji:

$2 X_{1 t}+2 X_{2 t}+4 X_{3 t} \leq 3000$

Bonggol pisang:

$0.02 X_{1 t} \leq 10$

Kapur sirih;

$8 X_{1 t} \leq 4000$

Cabe:

$2 X_{3 t} \leq 500$

Pare:

$8 X_{2 t} \leq 3000$

Minyak goreng:

$0.01 X_{1 t}+0.01 X_{2 t}+0.01 X_{3 t} \leq 12$

Bawang putih:

$1 X_{1 t}+1 X_{2 t}+1 X_{3 t} \leq 1000$

Garam:

$1 X_{1 t}+1 X_{2 t}+1 X_{3 t} \leq 1000$

Gula:

$1 X_{1 t}+1 X_{2 t}+1 X_{3 t} \leq 1000$

4) Kendala kapasitas produksi

Kendala kapasitas produksi dibuat berdasarkan persamaan 4 untuk setiap jenis produk.

Keripik bonggol pisang:

$X_{1 t} \leq 430$

Keripik pare:

$X_{2 t} \leq 417$

Peyek cabe:

$X_{3 t} \leq 430$

5) Kendala kapasitas gudang 
Kendala kapasitas gudang dibuat berdasarkan persamaan 5 untuk setiap jenis produk.

Keripik bonggol pisang:

$I_{1 t} \leq 100$

Keripik pare:

$I_{2 t} \leq 100$

Peyek cabe:

$I_{3 t} \leq 100$

\section{d. Analisis Hasil Running dengan LINGO}

Model matematis yang telah dibangun diinputkan ke dalam software LINGO untuk mendapatkan nilai solusi optimal. Berdasarkan hasil running dengan LINGO didapatkan jumlah produksi dan inventori optimal untuk masingmasing produk pada setiap periode yaitu selama 25 periode. Hasil yang didapatkan mampu meminimalkan total biaya yang harus dikeluarkan perusahaan yaitu sebesar Rp. 98.227.900. Agar selalu dapat memenuhi permintaan, selain menentukan jumlah produksi optimal, juga ditentukan jumlah inventori optimal. Hal ini disebabkan adanya kemungkinan permintaan dalam sehari tidak bisa langsung dipenuhi dari jumlah produksi sehari karena adanya berbagai batasan.

UMKM Al-Barik selama ini melakukan penentuan jumlah produksi dan inventori hanya berdasarkan perkiraan saja. Tabel 5, 6, dan 7 menunjukkan perbandingan jumlah produksi dan inventori yang sudah dilakukan oleh UMKM Al-Barik dan jumlah produksi dan inventori optimal hasil dari Linear Programming dengan LINGO.

Berdasarkan Tabel 5 dapat dilihat bahwa jumlah produksi yang dihasilkan lebih mendekati permintaan dan inventory yang diperoleh lebih sedikit atau cenderung tidak ada namun tetap bisa memenuhi permintaannya dan tidak menyebabkan lost sales. Total biaya yang merupakan total biaya produksi dan inventori yang telah dikeluarkan oleh UMKM AIBarik selama 25 periode untuk produk keripik bonggol pisang yaitu sebesar Rp. 38.180.846.

Tabel 5. Perbandingan jumlah produksi dan inventori optimal dengan kondisi riil untuk keripik bonggol pisang

\begin{tabular}{|c|c|c|c|c|c|}
\hline \multicolumn{6}{|c|}{ Hasil Output Keripik Bonggol Pisang } \\
\hline \multirow{2}{*}{$\mathbf{t}$} & \multirow{2}{*}{ Permintaan } & \multicolumn{2}{|c|}{ Produksi } & \multicolumn{2}{|c|}{ Inventori } \\
\hline & & Riil & Optimasi & Riil & Optimasi \\
\hline 0 & & & & 50 & \\
\hline 1 & 385 & 400 & 335 & 15 & \\
\hline 2 & 400 & 380 & 400 & & \\
\hline 3 & 355 & 300 & 355 & & \\
\hline 4 & 335 & 350 & 335 & 15 & \\
\hline 5 & 280 & 330 & 280 & 65 & \\
\hline 6 & 360 & 320 & 360 & 25 & \\
\hline 7 & 360 & 300 & 400 & & 40 \\
\hline 8 & 460 & 360 & 420 & & \\
\hline 9 & 270 & 320 & 270 & 50 & \\
\hline 10 & 280 & 340 & 280 & 110 & \\
\hline 11 & 360 & 310 & 360 & 60 & \\
\hline 12 & 380 & 340 & 380 & 20 & \\
\hline 13 & 400 & 390 & 400 & 10 & \\
\hline 14 & 310 & 400 & 382 & 100 & 72 \\
\hline 15 & 480 & 380 & 408 & & \\
\hline 16 & 370 & 320 & 370 & & \\
\hline 17 & 280 & 310 & 280 & 30 & \\
\hline 18 & 310 & 330 & 364 & 50 & 54 \\
\hline 19 & 460 & 380 & 406 & & \\
\hline 20 & 330 & 360 & 330 & 30 & \\
\hline 21 & 360 & 400 & 374 & 70 & 14 \\
\hline 22 & 380 & 370 & 410 & 60 & 44 \\
\hline 23 & 450 & 380 & 420 & & 14 \\
\hline 24 & 420 & 400 & 406 & & \\
\hline 25 & 320 & 360 & 320 & 40 & \\
\hline & otal Biaya & Rp. 38.009 .439 & Rp. 38.810.337 & Rp. 171.407 & Rp.50.993 \\
\hline
\end{tabular}


Jumlah ini lebih kecil dibandingkan dengan total biaya hasil optimasi yaitu Rp. 38.861.330. Meskipun begitu, pada kondisi riil yang diterapkan oleh UMKM AI-Barik masih terdapat lost sales pada beberapa periode. Jika perhitungan jumlah produksi dan inventori dilakukan dengan optimasi menggunakan Linear Programming maka permintaan tiap periode dapat terpenuhi. Total biaya inventori juga akan mengalami penurunan sebesar $70,25 \%$. Fatma (2019), menjelaskan bahwa biaya simpan inventori akan mempengaruhi total biaya keseluruhan yang harus dikeluarkan perusahaan.

Tabel 6 menunjukkan perbandingan jumlah produksi dan inventori optimal terhadap kondisi riil untuk produk keripik pare. Berdasarkan Tabel 6 , total biaya yang merupakan total biaya produksi dan inventori yang telah dikeluarkan oleh UMKM Al-Barik selama 25 periode untuk produk keripik pare yaitu sebesar Rp. 33.617.986. Apabila UMKM Al-Barik menentukan jumlah produksi dan optimasi dengan Linear Programming maka total biayanya menjadi lebih rendah yaitu sebesar Rp. $\quad 33.509 .966$ dan dapat memenuhi permintaan di setiap periode. Total biaya inventori juga akan mengalami penurunan sebesar 99,4\%.

Tabel 7 menunjukkan perbandingan jumlah produksi dan inventori optimal terhadap kondisi riil untuk produk peyek cabai. Berdasarkan Tabel 7 , total biaya yang merupakan total biaya produksi dan inventori yang telah dikeluarkan oleh UMKM Al-Barik selama 25 periode untuk produk peyek cabai yaitu sebesar $\mathrm{Rp}$. 26.009.331. Jumlah ini lebih kecil dibandingkan dengan total biaya hasil optimasi yaitu Rp. 25.151.109. Meskipun begitu, pada kondisi riil yang diterapkan oleh UMKM AI-Barik masih terdapat lost sales pada beberapa periode. Jika perhitungan jumlah produksi dan inventori dilakukan dengan optimasi menggunakan Linear Programming maka permintaan tiap periode dapat terpenuhi. Total biaya inventori juga akan mengalami penurunan sebesar $78,69 \%$.

Tabel 6. Perbandingan jumlah produksi dan inventori optimal dengan kondisi riil untuk keripik pare

\begin{tabular}{|c|c|c|c|c|c|}
\hline \multicolumn{6}{|c|}{ Hasil Output Keripik Pare } \\
\hline \multirow{2}{*}{$\mathbf{t}$} & \multirow{2}{*}{ Permintaan } & \multicolumn{2}{|c|}{ Produksi (bungkus) } & \multicolumn{2}{|c|}{ Inventori (bungkus) } \\
\hline & & Riil & Optimasi & Riil & Optimasi \\
\hline 0 & & & & 40 & \\
\hline 1 & 250 & 300 & 240 & 50 & \\
\hline 2 & 295 & 320 & 295 & 75 & \\
\hline 3 & 270 & 250 & 270 & 55 & \\
\hline 4 & 340 & 310 & 345 & 25 & 5 \\
\hline 5 & 380 & 340 & 375 & & \\
\hline 6 & 300 & 290 & 300 & & \\
\hline 7 & 340 & 280 & 340 & & \\
\hline 8 & 310 & 320 & 310 & 10 & \\
\hline 9 & 280 & 310 & 280 & 40 & \\
\hline 10 & 260 & 290 & 260 & 70 & \\
\hline 11 & 330 & 320 & 330 & 60 & \\
\hline 12 & 340 & 350 & 340 & 70 & \\
\hline 13 & 270 & 290 & 270 & 90 & \\
\hline 14 & 270 & 280 & 270 & 100 & \\
\hline 15 & 360 & 270 & 360 & 10 & \\
\hline 16 & 330 & 320 & 330 & & \\
\hline 17 & 300 & 310 & 300 & 10 & \\
\hline 18 & 300 & 340 & 300 & 50 & \\
\hline 19 & 360 & 330 & 360 & 20 & \\
\hline 20 & 340 & 310 & 340 & & \\
\hline 21 & 310 & 320 & 310 & 10 & \\
\hline 22 & 320 & 340 & 320 & 30 & \\
\hline 23 & 310 & 290 & 310 & 10 & \\
\hline 24 & 330 & 300 & 330 & & \\
\hline 25 & 300 & 320 & 300 & 20 & \\
\hline & otal Biaya & Rp. 33.444.074 & Rp. 33.508.886 & Rp. 173.912 & Rp. 1.080 \\
\hline
\end{tabular}


Tabel 7. Hasil Output Produksi Optimal Peyek Cabe (Perbungkus)

\begin{tabular}{|c|c|c|c|c|c|}
\hline \multicolumn{6}{|c|}{ Hasil Output Peyek Cabe } \\
\hline \multirow{2}{*}{$\mathbf{t}$} & \multirow{2}{*}{ Permintaan } & \multicolumn{2}{|c|}{ Produksi } & \multicolumn{2}{|c|}{ Inventory } \\
\hline & & Riil & Optimasi & Riil & Optimasi \\
\hline 0 & & & & 25 & \\
\hline 1 & 200 & 250 & 185 & 50 & \\
\hline 2 & 220 & 190 & 250 & 20 & 30 \\
\hline 3 & 280 & 240 & 250 & & \\
\hline 4 & 220 & 240 & 220 & 20 & \\
\hline 5 & 235 & 230 & 235 & 15 & \\
\hline 6 & 220 & 210 & 220 & 5 & \\
\hline 7 & 240 & 250 & 240 & 15 & \\
\hline 8 & 200 & 200 & 220 & 15 & \\
\hline 9 & 250 & 210 & 250 & & \\
\hline 10 & 240 & 230 & 240 & & \\
\hline 11 & 250 & 220 & 250 & & \\
\hline 12 & 220 & 240 & 220 & 20 & \\
\hline 13 & 250 & 200 & 250 & & \\
\hline 14 & 190 & 210 & 190 & 20 & \\
\hline 15 & 215 & 220 & 215 & 25 & \\
\hline 16 & 250 & 230 & 250 & 5 & \\
\hline 17 & 230 & 230 & 240 & 5 & 10 \\
\hline 18 & 260 & 230 & 250 & & \\
\hline 19 & 220 & 210 & 220 & & \\
\hline 20 & 235 & 240 & 240 & 5 & 5 \\
\hline 21 & 235 & 210 & 250 & 30 & 20 \\
\hline 22 & 270 & 230 & 250 & & \\
\hline 23 & 230 & 240 & 230 & 10 & \\
\hline 24 & 250 & 250 & 250 & 10 & \\
\hline 25 & 230 & 210 & 230 & 10 & \\
\hline & otal Biaya & Rp. 25.083.208 & Rp. 25.994.860 & Rp. 67.901 & Rp. 14.471 \\
\hline
\end{tabular}

Perhitungan jumlah produksi dan inventori yang dilakukan tanpa menggunakan optimasi menyebabkan terjadi lost sales pada beberapa periode. Hal ini membuat jumlah keuntungan yang didapatkan oleh UMKM Al-Barik menjadi tidak maksimal. Hasil optimasi yang dilakukan membuat semua permintaan konsumen dapat terpenuhi sehingga tidak terjadi lost sales. Tabel 8 menunjukkan perbandingan total keuntungan berdasarkan hasil optimasi dan kondisi riil untuk tiap produk selama 25 periode. Total keuntungan berdasarkan hasil optimasi didapatkan dari jumlah permintaan produk dikalikan dengan keuntungan setiap produk dan dikurangi dengan total biaya inventori, sedangkan total keuntungan pada kondisi riil merupakan jumlah permintaan yang dapat dipenuhi dikalikan dengan keuntungan setiap produk dan dikurangi dengan total biaya inventori. Dengan harga jual masing-masing produk sebesar Rp. 10.000, maka keuntungan produk keripik bonggol pisang, keripik pare, dan peyek cabai adalah Rp. 5.715 , Rp. 5.679 , dan Rp. 5.547

Tabel 8. Perbandingan total keuntungan produk antara kondisi riil dan optimasi

\begin{tabular}{|l|c|c|}
\hline \multicolumn{1}{|c|}{ Produk } & $\begin{array}{c}\text { Riil } \\
\text { (Rp.) }\end{array}$ & $\begin{array}{c}\text { Optimasi } \\
\text { (Rp.) }\end{array}$ \\
\hline $\begin{array}{l}\text { Keripik bonggol } \\
\text { pisang }\end{array}$ & 50.301 .273 & 51.639 .662 \\
\hline Keripik pare & 43.555 .925 & 44.041 .113 \\
\hline Peyek cabe & 31.116 .792 & 32.355 .140 \\
\hline Total & 124.973 .990 & 128.035 .915 \\
\hline
\end{tabular}

Berdasarkan Tabel 8 diketahui bahwa terdapat peningkatan keuntungan yang didapatkan dengan menggunakan optimal untuk setiap jenis produksi. Hal ini disebabkan permintaan produk setiap periode akan selalu dapat dipenuhi dengan menggunakan optimasi. Peningkatan total keuntungan yang didapatkan yaitu sebesar Rp.3.061.925 dalam 25 periode atau sebulan. Melalui optimasi penentuan jumlah produksi dan inventori dengan menggunakan Linear Programming, UMKM 
mampu memenuhi semua permintaan produk dari konsumen dengan tetap meminimalkan biaya simpan produk.

\section{Kesimpulan}

Penggunaan optimasi dengan Linear Programming terbukti dapat meminimalkan total biaya yang harus dikeluarkan, terutama biaya simpan. Rata-rata penurunan biaya simpan yang didapatkan dengan menggunakan optimasi yaitu sebesar $82,8 \%$ selama 25 periode atau sebulan. Perhitungan dengan optimasi juga terbukti dapat meningkatkan keuntungan karena tidak ada lost sales yang terjadi. Peningkatan keuntungan yang didapatkan dari hasil optimasi yaitu sebesar Rp.3.061.925 dalam 25 periode atau sebulan.

\section{Daftar Pustaka}

Akhmad, K. A., Karsidi, R., Rahayu, E. S., \& Wijaya, M. (2018). The Role of Government Policy in SMEs Facilitating Institutions in Indonesia : a Case Study on Business. 4(1), 12-15.

Andriani, M., Samadhi, T. M. A. A., Siswanto, J., \& Suryadi, K. (2017). Aligning business process maturity level with SMEs growth in Indonesian fashion industry. International Journal of Organizational Analysis, 26(4).

Christian, S. (2013). Penerapan Linear Programming untuk Mengoptimalkan Jumlah Produksi dalam Memperoleh Keuntungan Maksimal pada CV Cipta Unggul Pratama. Journal The WINNERS, 14(1), 55-60.

Fathurohman, A. (2019). Penentuan Jumlah Produksi dan Strategi Pemasaran Produk Pakaian Wanita IKM Rahmat di Jakarta. Jurnal Media Teknologi. 06(01), 11-36.

Fatma, E. (2019). Minimalisasi Biaya Simpan Dan Biaya Setup Pada Multiple Produk: Simulasi Dengan Capacitated Lot Sizing Problem. Jurnal Riset Manajemen Dan Bisnis (JRMB), 4(2), 205-214.

Haslan, R., Supriadi, N., \& Nasution, S. P. (2018). Optimalisasi Produksi Kopi Bubuk Asli Lampung Dengan Metode Simpleks. Jurnal Matematika, 17(2), 25-34.

Maghfirah, M., \& Syam, F. (2016). Analisis Perhitungan Harga Pokok Produksi dengan Penerapan Metode Full Costing pada UMKM Kota Banda Aceh. Jurnal IImiah Mahasiswa Ekonomi Akuntansi, 1(2), 59-70.

Mahardika, A. P., Ardiansyah, M. N., \& Yunus, E. D. S. (2017). Pengendalian Persediaan Untuk Mengurangi Biaya Total Persediaan Dengan Pendekatan Metode Periodic Review (R,s,S) Power Approximation Pada Suku Cadang Consumable (Studi Kasus : Job Pertamina Talisman Jambi Merang). Jurnal Rekayasa Sistem Industri, 4(1), 8.

Mitchell, F., \& Reid, G. C. (2000). Editorial. Problems, challenges and opportunities: The small business as a setting for management accounting research. Management Accounting Research, 11(4), 385-390.

Moeuf, A., Pellerin, R., Lamouri, S., TamayoGiraldo, S., \& Barbaray, R. (2018). The industrial management of SMEs in the era of Industry 4.0. International Journal of Production Research, 56(3), 1118-1136.

Puspitasari, M., Saptadi, S., \& Puspitasari, D. (2012). Pengembangan Model Matematis Untuk Optimasi Perencanaan Produksi Minuman Marimas. J@Ti Undip: Jurnal Teknik Industri, 2(1), 55-64. 4

Rachman, R. (2017). Optimalisasi Produksi Di Industri Garment Dengan Menggunakan Metode Simpleks. Jurnal Informatika, 4(1), 12-20.

Samudra, M., Arisandhy, V., \& Heryanto, R. M. (2019). Pengendalian Persediaan Obat Ternak untuk Meminimasi Total Biaya Persediaan di PT X. Journal of Integrated System, 2(1), 82-97.

Wardiyanta, W., Sudarmadji, S., \& Nopirin, N. (2017). Studi Eksploratif Mengenai Yogyakarta sebagai Pengirim Wisatawan Keluarga. Jurnal IImu Sosial Dan IImu Politik, 20(1), 84-96.

Yanah, Y., Nakhwatunnisa, H., \& Sukarno, T. A. (2018). Strategy to Increase the Competitiveness of SME's Entreprises. Jurnal Ekonomi Dan Kebijakan, 11(1), 138-150. 
DOI: https://doi.org/10.26593/jrsi.v10i1.4491.15-26

Halaman ini sengaja dikosongkan.

This page is intentionally left blank. 